\title{
Management of chronic pain in osteoporosis: challenges and solutions
}

This article was published in the following Dove Press journal: Journal of Pain Research

I April 2016

Number of times this article has been viewed

\section{Teresa Paolucci* \\ Vincenzo Maria Saraceni Giulia Piccinini*}

Physical Medicine and Rehabilitation Unit, Azienda Policlinico Umberto I, Rome, Italy

*These authors contributed equally to this work
Correspondence: Teresa Paolucci Complex Unit of Physical Medicine and Rehabilitation, Azienda Policlinico Umber to I, Piazzale Aldo Moro 5, 00185 Rome, Italy

Tel +393479338625

Fax +390649914552

Email teresapaolucci@hotmail.com
Abstract: Osteoporosis (OP) is a pathological condition that manifests clinically as pain, fractures, and physical disability, resulting in the loss of independence and the need for longterm care. Chronic pain is a multidimensional experience with sensory, affective, and cognitive aspects. Age can affect each of these dimensions and the pain that is experienced. In OP, chronic pain appears to have sensory characteristics and properties of nociceptive and neuropathic pain. Its evaluation and treatment thus require a holistic approach that focuses on the specific characteristics of this population. Pain management must therefore include pharmacological approaches, physiotherapy interventions, educational measures, and, in rare cases, surgical treatment. Most rehabilitative treatments in the management of patients with OP do not evaluate pain or physical function, and there is no consensus on the effects of rehabilitation therapy on back pain or quality of life in women with OP. Pharmacological treatment of pain in patients with OP is usually insufficient. The management of chronic pain in patients with OP is complicated with regard to its diagnosis, the search for reversible secondary causes, the efficacy and duration of oral bisphosphonates, and the function of calcium and vitamin D. The aim of this review is to discuss the most appropriate solutions in the management of chronic pain in OP.

Keywords: physical therapy, exercise, pharmacological treatment, posture and balance

\section{Introduction}

Osteoporosis (OP) is a pathological condition that is characterized by a bone mineral density (BMD) level that is $2.5 \mathrm{SD}$ (standard deviation) or more below the mean value (T-score $=-2.5$ ) for a young adult. OP comprises a heterogeneous group of syndromes in which the bone mass per unit volume is decreased in otherwise normal bones, rendering them more fragile and increasing their risk of fractures. ${ }^{1,2}$ The vertebral bodies, proximal end of the femur, distal end of the radius, and proximal end of the humerus are the sites that are most commonly affected by fragility fractures.

OP can manifest clinically as pain, fractures, and physical disability, resulting in the loss of independence and the need for long-term care. Recent studies have reported the prevalence of OP and osteopenia to be $10 \%$ and $36 \%$ in men aged between 60 years and 79 years and $18.5 \%$ and $44.7 \%$ in women aged between 40 years and 79 years, respectively, and an estimated 22 million women and 5.5 million men are affected by OP in the European Union. ${ }^{3,4}$

In elderly persons, OP and sarcopenia are often associated in both conditions, the number and size of muscle fibers are reduced, and there is a preferential loss of type II fibers. ${ }^{5}$ Partial or complete age-related immobilization also increases the risk of muscle 
atrophy and bone loss, boosting the risk of fractures. The elderly are at greater risk of debilitating postural changes due to several factors, particularly, the involutional loss of functional muscle motor units and the higher prevalence of OP in these subjects. Moreover, as noted by Sinaki, this muscle loss can contribute to OP-related skeletal changes in this population. ${ }^{6}$ Muscle weakness has been suggested to be related to a progressive decline in bone mass, with consequent axial kyphosis, even in the absence of vertebral fractures. ${ }^{7}$ Based on these findings, chronic pain can result from OPinduced skeletal deformities, joint imbalance, and tension in muscular structures. Often, the most common symptom in patients with OP is severe or intolerable back pain. Large population studies have reported a link between low back pain (LBP) and OP, especially in the elderly. ${ }^{8-11}$

Over time, bone fragility can accelerate the onset of multiple fractures, causing a progressive loss of stature and continuous contraction of the paravertebral muscles in maintaining posture. This sequence of events results in muscle fatigue and pain that can persist, even after the fractures have healed. ${ }^{12}$ Furthermore, with age, the perception and response to pain change for reasons that remain unknown. According to many groups, the pain threshold increases in elderly people..$^{13,14}$

The frequency of chronic pain usually rises with age, affecting $41 \%$ of persons aged $65-75$ years, $48 \%$ of those aged $75-84$ years, and $55 \%$ of persons aged $>85$ years.

Based on several theories, long-term pain is the product of perceptive discoherence and, consequently, the loss of the ability to integrate sensory information.

Thus, pain is a type of feedback that raises one's awareness and causes discomfort in activating mechanisms of homeostatic recovery. ${ }^{15}$ As discussed by Craig, ${ }^{16}$ pain can also be considered the result of the output of a widely distributed neural network in the brain, rather than the direct effect of sensory input that is evoked by an injury.

Chronic pain in OP has sensory characteristics (such as postural alterations, fractures, and muscle atrophy) and properties of nociceptive and neuropathic pain. ${ }^{17}$ Chronic pain is a multidimensional experience with sensory, affective, and cognitive aspects, all of which interact and contribute to the final response of an individual who is subjected to pain. Age can affect each of these dimensions and the pain that is experienced. Moreover, the sensation of chronic pain can be altered by memory, expectations, and emotions. ${ }^{18,19}$

The evaluation and treatment of chronic pain in patients with OP thus require a holistic approach that focuses on the specific characteristics of this population, assessing their comorbidities, mental status, functional status, and independence in carrying out daily activities. Pain management must therefore include pharmacological approaches, physiotherapy interventions, and in rare cases, surgical treatment. Most rehabilitative treatments in the management of patients with OP do not evaluate pain or physical function. ${ }^{20}$ Rehabilitation treatments that are based on exercises help manage these symptoms quickly without generating significant adverse effects or contraindications. ${ }^{21}$

Despite the development of guidelines on the diagnosis and treatment of $\mathrm{OP}^{22}$ the management of chronic pain in these patients remains complicated. The aim of this review was to discuss the most appropriate solutions in the management of chronic pain in OP, considering recent scientific evidence on pharmacological and nonpharmacological therapies and surgical treatment.

\section{Nonpharmacological therapy Physical exercise}

Compared with earlier beliefs, the sole purpose of rehabilitative exercises in OP is not merely to preserve or increase bone mass. Complementary and alternative approaches, such as yoga and pilates, have been proposed to improve function and reduce chronic pain in the spine.

It is essential that all exercises be performed safely, with a gradual progression of difficulty, avoiding bending and rotation of the trunk, which might be harmful and aggravate back pain. ${ }^{23}$ Taking these precautions into consideration, according to Tüzün et al, ${ }^{24}$ yoga is an approach that has a positive effect on pain and has physical and social benefits for patients with OP. Pilates exercises increase BMD, improve quality of life and walking distances, and relieve pain, and can thus be offered to patients with OP. ${ }^{25}$ As reviewed by Wei et al, ${ }^{26} \mathrm{a}$ Wuqinxi-based exercise program of at least 6 months, five times per week for 30-60 minutes each session, can improve pain symptoms.

The standard rehabilitation treatment in patients with OP is based on correcting postural changes, preventing falls by improving balance and coordination, relieving pain, and enhancing one's psychological well-being. Frequently, group rehabilitation is proposed to teach the exercises to the patient, allowing him or her to repeat them autonomously at home. ${ }^{27}$ A recent study ${ }^{28}$ noted that group rehabilitation exercises reduce back pain and improve functional status and quality of life in postmenopausal women with OP, the results of which were maintained for up to 6 months after the end of treatment.

A recently proposed rehabilitation program considered national guidelines and recommendations on interventions 
that aim to prevent and treat postmenopausal OP. ${ }^{27}$ The exercises included muscular stretching exercises and balance strengthening of antigravity muscles and were conducted with greater difficulty and intensity. All strengthening exercises and flexibility sessions ended with stretching exercises.

Bergland et $\mathrm{al}^{29}$ suggested that exercise-based treatment in persons with spinal OP is beneficial and is associated with less pain and better quality of life, strength, and balance. Interventions ranged from simple back extension exercises to various general weight-bearing exercises, balance activities, and stretches that were combined with upper limb, trunk, and lower limb strengthening. The interventions were delivered in a class format, as a home program or as a combination of physiotherapist-led sessions and home exercise programs. There was no evidence that any of these delivery options was superior to another. ${ }^{30-36}$

von Stengel et al and Kronhed et al concluded that power training is superior to strength training in maintaining BMD in postmenopausal women. ${ }^{37,38}$

Exercises for improving axial stability include a back extension exercise program. When fragility is resolved, as Sinaki reported, back extension is performed against resistance that is applied to the upper back. The exercise regimen must always correspond to the needs of the patient: in general, an exercise program - therapeutic or recreational - must target flexibility, muscle strength, core stability, cardiovascular fitness, and gait steadiness. ${ }^{10,39}$

The use of tape, in association with back exercise, was recently shown to lower pain in OP: in postural taping, tape is applied to the skin to increase proprioceptive feedback on postural alignment, improve thoracic extension, reduce pain, and facilitate muscle activity and postural balance. ${ }^{40}$

Postural deformities and imbalances, which occur typically in OP, are associated with muscle contractures of the spine, and soft manual tissue massage therapy with exercises improves the perceived change in back pain in these patients. Bennell et $\mathrm{al}^{41}$ proposed soft tissue massage and passive accessory central posterior-anterior mobilization techniques for the thoracic spine.

\section{Physical therapy}

Physical therapy, such as the use of magnetic fields and vibration training, has been administered to treat patients with OP. There is little evidence on the use of magnetic fields in chronic pain that is associated with OP. A review by Huang et $\mathrm{al}^{42}$ concluded that low-frequency PEMFs (pulsed electromagnetic fields) relieve the pain of primary OP quickly and efficiently.
Vibration training can treat OP-induced pain and improve physical fitness by increasing muscle strength, neuromuscular coordination, and balance and reducing the risk of falls, which often result in fractures, as reported by Iwamoto et al. ${ }^{43,44}$ The analgesic effects of whole-body vibration have also been confirmed in two other studies. ${ }^{45,46}$ Based on these inconsistent results, it is difficult to determine the appropriate range of frequencies for obtaining the positive effects of this therapy. However, the therapy must be initiated at lower vibration frequencies, increasing gradually throughout the therapy. ${ }^{47}$

Other forms of nonpharmacological therapy that have been suggested for the management of chronic pain include cognitive-behavioral therapy and mindfulness-based interventions. Cognitive-behavioral therapy is a form of psychotherapy that is used to deepen the understanding of one's pain and teach self-control and coping strategies (extinguishing maladaptive behavior and reinforcing positive reactions to pain). It improves pain and quality of life and reduces disabilities in patients who suffer from chronic pain ${ }^{48}$ and has strong therapeutic effects against chronic LBP. ${ }^{49}$

Mindfulness-based interventions are based on the separation of the sensory and emotional aspects of pain and the promotion of awareness of bodily and psychological sensations within the body. Through mindful awareness and meditation, thoughts on pain can be viewed as discrete events rather than as a problem that necessitates possibly maladaptive responses. These interventions are traditionally structured as 2-hour sessions every week for a minimum of 10 weeks to establish awareness of the body, proprioceptive signals, breath, and physical sensations and develop mindful activities (such as eating, walking, and standing). ${ }^{50}$

\section{Pharmacological therapy}

Chronic pain is a major public health concern with significant economic, social, and medical impacts. In the past several decades, public health authorities have recorded increased access to the emergency department and greater morbidity and mortality, secondary to medical and nonmedical overuse of pain relievers, especially opioids. ${ }^{51}$

Choosing the appropriate analgesic should always be based on the intensity of chronic pain that is reported by the patient. ${ }^{52}$ For cases of mild pain (numeric rating scale [NRS] $\leq 3$ ), nonsteroidal anti-inflammatory drugs (NSAIDs) or acetaminophen is recommended, with the possibility of augmenting with adjuvants; for those with moderate pain (NRS 4-6), weak opioids with or without NSAIDs or acetaminophen are suggested, with the option of adjuvant therapy; 
and those with strong pain $(\mathrm{NRS}>6)$ should be treated with opioids and NSAIDs or acetaminophen, with possible supplementation with adjuvants. Adjuvant drugs are a class of molecules that contribute to mitigating pain, increasing the effects of analgesics. ${ }^{53}$

In any case, based on the possible adverse effects, abuse, and addiction that might result from the use of certain drugs, especially opioids, it is always advisable to resort to pharmacological therapy only after nonpharmacological therapies have failed, eventually combining the two therapies (multimodal therapy) in cases of pain that are persistent and resistant to nonpharmacological treatments in augmenting and complementing the pharmacological treatment. The most frequently recommended first-line nonpharmacological therapies are physical exercises performed individually or in group initially under the guidance of a therapist and later independently at home; gymnastic and breathing activities, such as yoga and pilates; cognitive-behavioral therapy; mindfulness-based pain management; and physical therapies, such as magnetic fields, analgesic stimulation, and vibration therapy.

This treatment strategy is recommended especially for pain in patients with OP without fractures, whereas those with fractures should consider a combination of pharmacological and nonpharmacological therapies. Bisphosphonates appear to be effective; in particular, intravenous pamidronate ${ }^{54}$ has sustained analgesic effects and reduces acute back pain due to recent osteoporotic vertebral fractures. In these patients, teriparatide also lowered the risk of new or worsening back pain. ${ }^{55}$

\section{NSAIDs and opioids}

NSAIDs are widely used for chronic pain that is associated with fragility fractures. Nevertheless, the treatment of pain in such patients is rarely considered a priority in the therapeutic management. ${ }^{56}$ Yet, in patients with OP with chronic pain, these agents have negative effects on bone metabolism and thus should not be considered first-line drugs for long periods. An estimated $70 \%$ of elderly patients and $~ 20 \%$ of hospitalized patients are treated with NSAIDs. ${ }^{57}$ Vestergaard et al noted that patients who take NSAIDs experience more fractures than expected. ${ }^{58}$

The pharmacological action of NSAIDs and celecoxib on cyclooxygenase can have a profound effect on skeletal health, although this enzyme appears to mediate the healing of skeletal tissue, directly or indirectly, by modulating the inflammatory response.
Also, acetaminophen, the most widely prescribed analgesic and antipyretic, is associated with an increased risk of fractures, the mechanisms of which are unknown. ${ }^{59}$ Treatment of pain with a peripherally acting drug, such as ibuprofen, can reduce the chronic pain that is associated with OP more effectively than a centrally acting medication, such as tramadol. Thus, it is advisable to prescribe ibuprofen rather than tramadol to treat OP-associated chronic pain in postmenopausal women, taking into account the risk of gastrointestinal side effects. ${ }^{60}$

Opioids can be used to relieve moderate-to-severe OPassociated pain that is inadequately managed with more conservative or interventional methods. They are not a firstline therapy and must be taken for short periods with close monitoring to limit the risk of side effects. ${ }^{61}$ Approximately $50 \%$ of all opioid users experience at least one side effect, and $>20 \%$ discontinue treatment due to a serious adverse event. ${ }^{57,62}$ Common side effects include constipation, nausea, vomiting, pruritus, delayed gastric emptying, dizziness, sedation, tolerance, and addiction.

In the treatment of moderate pain, the World Health Organization ${ }^{63}$ recommends weak opioids, primarily codeine and tramadol. The transdermal opioid patch is recommended for patients with continuous pain in whom oral administration is not possible. In opioid-naïve patients, treatment should be started at a low dose and titrated slowly to minimize the risk of related adverse effects. The use of long-acting opioids (eg, morphine) can provide more consistent pain relief, with less risk of addiction or abuse and better adherence. To better address the difficulties that are associated with the management of chronic pain, the physician should tailor the treatment after evaluating a patient's history of pain and its specific effects. ${ }^{64}$

\section{Vitamin D}

Vitamin D stimulates osteoblast activity; increases intestinal absorption of calcium from the diet, governing calcium metabolism and parathyroid hormone activity; and improves proximal muscle function. The rationale for vitamin $\mathrm{D}$ in the treatment of patients with OP is that improving skeletal health will reduce the risk of fractures and, consequently, pain. ${ }^{65}$ Vitamin D mitigates musculoskeletal pain and downregulates inflammatory markers in patients with postmenopausal OP, especially after the infusion of zoledronic acid. ${ }^{66}$ Persistent pain is associated with vitamin D-linked bone demineralization, myopathy, and musculoskeletal pain. Pain pathways that are associated with changes in cortical, immunological, 
hormonal, and neuronal levels are potentially influenced by vitamin D. ${ }^{67}$

\section{Antiresorptive drugs Denosumab}

Denosumab is a fully human monoclonal antibody that inhibits the differentiation and function of osteoclast precursors. It has been approved for postmenopausal patients who are at high risk of osteoporotic fractures. ${ }^{68}$ There is little evidence of the efficacy of denosumab against chronic pain in patients with OP. Denosumab decreases bone pain after 12 months of treatment, as evidenced by visual analog scale (VAS) scores, in patients with primary and secondary OP. In addition, 12-month treatment with denosumab increases BMD in the lumbar spine and total hip. ${ }^{69}$

\section{Bisphosphonates}

Bisphosphonates raise bone mass levels by inhibiting bone resorption and preventing fractures. ${ }^{70,71}$ They improve pain and quality of life in patients with OP, effects that are likely to be linked to their antiabsorptive activity and their capacity to suppress the production of neuropeptides, such as substance $P$ and calcitonin gene-related peptide, and inflammatory cytokines, such as tumor necrosis factor alpha. ${ }^{72}$

One bisphosphonate, alendronate, decreases pain and improves quality of life better than calcium in women with postmenopausal OP. Alendronate significantly reduces pain, based on VAS scores, and enhances quality of life compared with calcium supplementation alone. ${ }^{73}$ Alendronate increases BMD and significantly alleviates joint pain and any exacerbation of back pain, suggesting that reduction in pain contributes to improvements in overall quality of life in such patients. ${ }^{74}$ Another study confirmed the beneficial effects of alendronate on pain and quality of life in postmenopausal women with OP. ${ }^{75}$ Alendronate increases lumbar spine BMD and mitigates chronic back pain, suppressing bone resorption in postmenopausal women with $\mathrm{OP} .{ }^{73}$ Alendronate also lowers the need for analgesics and improves daily activity functioning and mobility of the spine in patients with postmenopausal OP. ${ }^{76}$ These effects suggest that switching to alendronate with cyclic etidronate leads to a greater change in lumbar BMD, bone resorption, and back pain compared with continuous treatment with cyclical etidronate in postmenopausal women with OP. ${ }^{77}$

Ibandronate significantly decreases pain and stiffness and improves functional motor failure in patients with $\mathrm{OP}$ and concomitant gonarthrosis. ${ }^{78}$ It can be administered orally and intravenously and has robust effects in alleviating bone pain. The oral and intravenous versions of ibandronate are well tolerated.

A study of patients who were treated with daily minodronate or weekly alendronate reported a significant reduction in pain, as measured on the VAS. ${ }^{79}$ However, the analgesic effects were observed in more minodronate-treated patients. Minodronate performs better than alendronate in limiting bone turnover and lowers back pain in the absence of gastrointestinal side effects. ${ }^{79}$ Risedronate also reduces pain and disability and improves quality of life, as assessed using the Short Form-36 survey, in postmenopausal osteoporotic women without vertebral fractures. ${ }^{80}$ The relationship between LBP and OP, in the absence of vertebral fractures, remains unknown. A decrease in bone resorption correlates with improved LBP, suggesting that despite the lack of vertebral fractures, the bone loss that is due to OP can cause back pain. ${ }^{80}$

Owing to their ability to improve the underlying pathogenesis of OP, bisphosphonates are considered to be a component of palliative therapy for bone pain that is associated with malignant diseases and also appear to be effective as analgesics in other nonmalignant conditions. A recent review describes the anti-inflammatory properties and the analgesic effect of clodronate with a good safety profile; it is shown to be effective on pain in patients with fragility fractures ${ }^{81}$ and to have a higher pain killer effect, compared to other analgesics, such as paracetamol, and other aminobisphosphonates, including neridronate. ${ }^{82}$

Intravenous pamidronate is efficacious against chronic back pain due to osteoporotic vertebral fractures. ${ }^{54}$ A study reported the efficacy of zoledronic acid in the treatment of pain in patients who were affected by LBP as a single intravenous infusion of $5 \mathrm{mg}$ compared with placebo at 1 month and recommended its use only in severe disabling LBP or when symptoms are not adequately controlled with pain medication and physiotherapy. ${ }^{83}$ Furthermore, in patients with postmenopausal OP, zoledronic acid reduced the number of days with back pain and limited activity due to back pain versus placebo. ${ }^{84}$

\section{Teriparatide}

Teriparatide is a human parathyroid hormone analog that stimulates osteoclasts to resorb bone and affects the generation of osteoblasts, inducing the formation of new bone. It lowers the incidence of vertebral and hip fractures and has been approved for OP in patients who are at high risk of 
Sensory-discriminative aspect

Permanent changes in the nervous structures responsible for the perception, transmission, and processing of nociceptive stimuli (pain matrix)

Biopsychosocial model Interaction between biological, psychological, and social factors

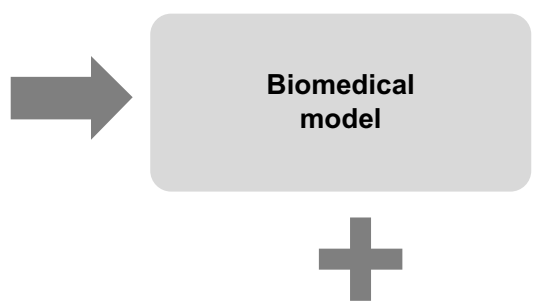
Affective-motivational aspect The pain is subjective, individual, and modified by the degree of attention, emotional states, and conditioning experience of past experiences

Figure I Mechanisms responsible for chronic pain. The interaction between permanent changes in the nociceptive system and individual psychosocial factors.

fractures. ${ }^{85,86}$ Eighteen months of treatment with teriparatide in patients with severe OP is associated with reduction in pain-related vertebral fractures and disability and constant and progressive improvement in quality of life, with clinically and statistically significant effects after 12 months of therapy. Although teriparatide does not alter the biomechanical factors that mediate the pathogenesis of spinal pain, it lowers the incidence of new micro- and macrofractures and strengthens the structure and quality of bone in the spine, mitigating pain and functional limitations and improving quality of life. ${ }^{87}$

A meta-analysis showed that teriparatide-treated patients with OP had a lower risk of new or worse pain in the lower back compared with those who received placebo, hormone replacement therapy, or alendronate. ${ }^{88}$ One study noted rapid and significant improvements in back pain and quality of life in patients who had been treated with teriparatide, effects that persisted after 18 months, also after the interruption of therapy, ${ }^{89}$ and another reported that teriparatide treatment was associated with a significant reduction in back pain. ${ }^{90}$

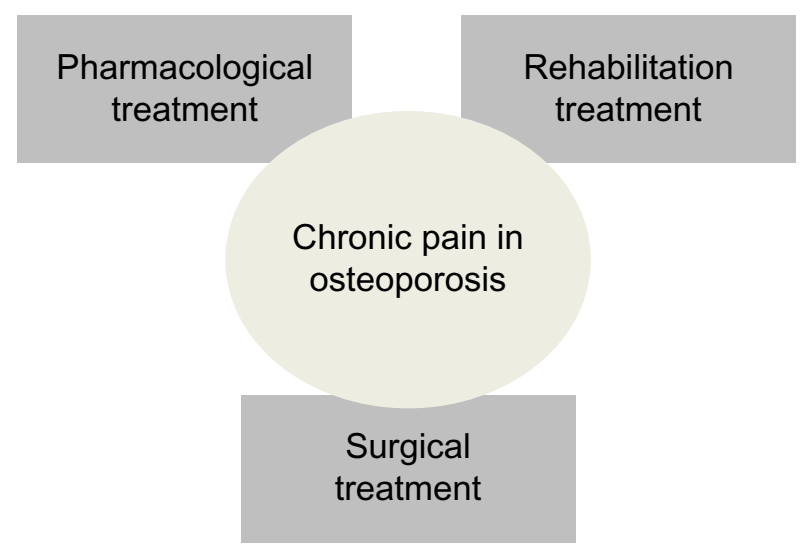

Figure 2 Pain management of chronic pain in patients with osteoporosis.
Patients with severe OP who were administered teriparatide, antiresorptives (raloxifene and bisphosphonates), or both reported significantly less LBP, although there were no differences between treatment groups with regard to the primary end point of the proportion of patients who experienced a $\geq 30 \%$ reduction in worst back pain at 6 months. ${ }^{91}$ Teriparatide significantly increases the density of bone mass, in terms of T-score, lowering the incidence of new fractures, improving the quality of life, and decreasing the consumption of NSAIDs. ${ }^{92}$

\section{Strontium ranelate}

Strontium ranelate increases BMD and tempers the risk of vertebral and nonvertebral fractures. It also enhances osteoblast function and suppresses osteoclast activity. ${ }^{93,94}$ Strontium ranelate significantly improves quality of life and pain compared with placebo. ${ }^{95}$ One study reported that strontium ranelate has a positive anabolic effect that accelerates the healing of fractures, causing the disappearance of secondary pain after several months of treatment. ${ }^{96}$ Strontium ranelate also reduces the risk of vertebral fractures by $33 \%$ over 4 years, with beneficial effects on quality of life and back pain, ${ }^{97}$ and is associated with significantly less back pain and analgesic use in men with primary OP. ${ }^{98}$

Long-term therapy with strontium ranelate decreases the risk of fractures and is well tolerated, with a low incidence of side effects, rendering it a suitable first-line treatment for postmenopausal women who are at high risk of fractures. It should be administered with caution in patients who are at risk of venous thromboembolism or have a rash. ${ }^{99}$

\section{Calcitonin}

Calcitonin is an endogenous polypeptide hormone that inhibits bone resorption by osteoclasts. It increases bone density in postmenopausal women, predominantly at 
the lumbar spine, and reduces the incidence of vertebral fractures. ${ }^{100}$

Few studies have demonstrated its efficacy in the treatment of chronic pain in patients with OP. A review on calcitonin in postmenopausal OP recommends short-term use, based on evidence of a link between calcitonin therapy and cancer. ${ }^{101}$ Calcitonin appears to mitigate pain by acting on the central nervous system, ${ }^{102}$ and when administered subcutaneously or intranasally, it has excellent analgesic effects in patients with vertebral fractures. ${ }^{103}$

\section{Raloxifene}

Raloxifene is a selective estrogen receptor modulator that has estrogen and estrogen-like effects on bone and antagonizes the action of estrogen in endometrium and breast tissue. Treatment with raloxifene in postmenopausal women with OP correlates with a marked reduction in skeletal pain and analgesic consumption and improved sleep quality. ${ }^{104}$ Clinical studies suggest that postmenopausal women who are on estrogen replacement therapy have a greater risk of developing LBP and its associated disability than those who are not taking estrogens. It appears that raloxifene has no influence on back pain or disability in women with postmenopausal OP. ${ }^{105}$ A recent retrospective database analysis ${ }^{104}$ noted similar improvements in fracture rates in cohorts of patients who were treated with alendronate or raloxifene, demonstrating a lower risk of breast cancer in those who were given raloxifene. The side effects of raloxifene include a greater risk of fatal stroke and venous thromboembolism. ${ }^{105}$

\section{Surgical treatments}

Percutaneous vertebroplasty is commonly used to treat vertebral fractures due to OP, and although its superiority over conservative treatment remains debated, it generates better results than conservative treatment with regard to pain and function in women aged $\geq 60$ years with OP. ${ }^{106} \mathrm{Up}$ to $51 \%$ of fractures in women and $24 \%$ of those in men are attributable to OP hip fractures and their resulting disabilities. ${ }^{107}$ Many patients with severe OP undergo hip arthroplasty, and good results have been obtained with cemented and uncemented femoral implants. Uncemented implants appear to be more affected by periprosthetic fractures, and both types are subject to a greater risk of dislocation. ${ }^{108}$

\section{Conclusion}

Today, a single-track approach to chronic pain in patients with $\mathrm{OP}$ is no longer conceivable. The standard modality in OP is to combine pharmacological and nonpharmacological therapies. Exercises for improving axial stability must always be proposed, and the exercise regimen should correspond to the needs of the patient, who has to be instructed by the therapist on home exercise programs to improve his self-management of chronic pain. As discussed, nonpharmacological treatments include various approaches (such as mind-body exercises) that have shown good efficacy. Other recommended approaches for the management of chronic pain are cognitive-behavioral therapy and mindfulness-based interventions to teach the patient to learn how to accept pain and find strategies to react to it properly. Concerning the recommendations on time course of drug in patients with chronic pain affected by OP, the generic precautions given in analgesics guidelines for each single drug should be applied. For example, the duration of therapy with paracetamol should not exceed 4-5 days in order to avoid adverse effects. In general, the therapy with analgesic and anti-inflammatory drugs must be limited to the shortest possible period of time. ${ }^{109}$

In conclusion, the preferred pharmacological treatment for chronic pain in patients with OP is bisphosphonates, particularly alendronate, followed by denosumab, strontium ranelate, and teriparatide.

\section{Disclosure}

The authors report no conflicts of interest in this work.

\section{References}

1. Kanis JA, McCloskey EV, Johansson H, Oden A, Melton LJ 3rd, Khaltaev N. A reference standard for the description of osteoporosis. Bone. 2008;42(3):467-475.

2. Tarantino U, Capone A, Planta M, et al. The incidence of hip, forearm, humeral, ankle, and vertebral fragility fractures in Italy: results from a 3-year multicenter study. Arthritis Res Ther. 2010;12(6):R226.

3. Maggi S, Noale M, Giannini S, et al; ESOPO Study Group. ESOPO Study Group Quantitative heel ultrasound in a population-based study in Italy and its relationship with fracture history: the ESOPO study. Osteoporos Int. 2006;17(2):237-244.

4. Ström O, Borgström F, Kanis JA, et al. Osteoporosis: burden, health care provision and opportunities in the EU: a report prepared in collaboration with the International Osteoporosis Foundation (IOF) and the European Federation of Pharmaceutical Industry Associations (EFPIA). Arch Osteoporos. 2011;6:59-155.

5. Tarantino U, Baldi J, Celi M, et al. Osteoporosis and sarcopenia: the connections. Aging Clin Exp Res. 2013;25(Suppl 1):S93-S95.

6. Sinaki M. Musculoskeletal challenges of osteoporosis. Aging (Milano). 1998;10(3):249-262.

7. Sinaki M, Brey RH, Hughes CA, Larson DR, Kaufman KR. Balance disorder and increased risk of falls in osteoporosis and kyphosis: significance of kyphotic posture and muscle strength. Osteoporos Int. 2005;16(8):1004-1010.

8. Fernández-de-las-Peñas C, Hernández-Barrera V, Alonso-Blanco C, et al. Prevalence of neck and low back pain in community-dwelling adults in Spain: a population-based national study. Spine. 2011;36:E213-E219.

9. Chou YC, Shih CC, Lin JG, Chen TL, Liao CC. Low back pain associated with sociodemographic factors, lifestyle and osteoporosis: a population-based study. J Rehabil Med. 2013;45(1):76-80. 
10. Sinaki M, Pfeifer M, Preisinger E, et al. The role of exercise in the treatment of osteoporosis. Curr Osteoporos Rep. 2010;8(3):138-144.

11. Nagae M, Hiraga T, Wakabayashi H, Wang L, Iwata K, Yoneda T. Osteoclasts play a part in pain due to the inflammation adjacent to bone. Bone. 2006;39(5):1107-1115.

12. Kim DH, Vaccaro AR. Osteoporotic compression fractures of the spine; current options and considerations for treatment. Spine J. 2006;6(5):479-487.

13. Gasik R, Styczyński T. Specifics of pharmacological treatment of back pains in people of old age. Polski Merkuliusz Lekarski. 2006;21(124):394-397.

14. Kołodziej W. Bio psycho social functioning of people in old age and social stereotypes and prejudice concerning ageing and old age. In: Nowicka A, editor. Selected Problems of People in Old Age. Kraków: Oficyna Wydawnicza Impuls; 2006 (55-71).

15. Melzack R. Pain and the neuromatrix in the brain. J Dent Educ. 2001;65(12):1378-1382.

16. Craig AD. Pain mechanisms: labeled lines versus convergence in central processing. Annu Rev Neurosci. 2003;26:1-30.

17. Dziechciaż M, Balicka-Adamik L, Filip R. The problem of pain in old age. Ann Agric Environ Med. 2013;(Spec no. 1):35-38.

18. Iannetti GD, Mouraux A. From the neuromatrix to the pain matrix (and back). Exp Brain Res. 2010;205(1):1-12.

19. Craig AD. How do you feel now? The anterior insula and human awareness. Nat Rev Neurosci. 2009;10(1):59-70.

20. Howe TE, Shea B, Dawson LJ, et al. Exercise for preventing and treating osteoporosis in postmenopausal women. Cochrane Database Syst Rev. 2011;7:CD000333.

21. Pedersen BK, Saltin B. The evidence for prescribing exercise as therapy in chronic disease. Scand J Med Sci Sports. 2006;16(Suppl 1):3-63.

22. Hernlund E, Svedbom A, Ivergård M, et al. Osteoporosis in the European Union: medical management, epidemiology and economic burden. A report prepared in collaboration with the International Osteoporosis Foundation (IOF) and the European Federation of Pharmaceutical Industry Associations (EFPIA). Arch Osteoporos. 2013;8:136.

23. Sinaki M. Yoga spinal flexion positions and vertebral compression fracture in osteopenia or osteoporosis of spine: case series. Pain Pract. 2013;13(1):68-75.

24. Tüzün S, Aktas I, Akarirmak U, Sipahi S, Tüzün F. Yoga might be an alternative training for the quality of life and balance in postmenopausal osteoporosis. Eur J Phys Rehabil Med. 2010;46(1):69-72.

25. Angin E, Erden Z, Can F. The effects of Clinical Pilates Exercises on bone mineral density (BMD), physical performance and quality of life of women with postmenopausal osteoporosis. J Back Musculoskelet Rehabil. 2015;28(4):849-858.

26. Wei X, Xu A, Yin Y, Zhang R. The potential effect of Wuqinxi exercise for primary osteoporosis: a systematic review and meta-analysis. Maturitas. 2015;82(4):346-354.

27. Bonaiuti D, Arioli G, Diana G, et al. SIMFER rehabilitation treatment guidelines in postmenopausal and senile osteoporosis. Eura Medicophys. 2005;41(4):315-337.

28. Paolucci T, Morone G, Iosa M, et al. Efficacy of group-adapted physical exercises in reducing back pain in women with postmenopausal osteoporosis. Aging Clin Exp Res. 2014;26(4):395-402.

29. Bergland A, Thoresen H, Kåresen R. Effect of exercise on mobility, balance, and health-related quality of life in osteoporotic women with a history of vertebral fracture: a randomised controlled trial. Osteoporos Int. 2010;22(6):1863-1871.

30. Chien YC, Yang RS, Tsauo JY. Home-based trunk-strengthening exercise for osteoporotic and osteopenic postmenopausal women without fracture-a pilot study. Clin Rehabil. 2005;19(1):28-36.

31. Gold DT, Shipp KM, Pieper CF, Duncan PW, Martinez S, Lyles KW. Group treatment improves trunk strength and psychological status in older women with vertebral fractures: results of a randomized clinical trial. J Am Geriatr Soc. 2004;52(9):1471-1478.

32. Hongo M, Itoi E, Sinaki M, et al. Effect of low-intensity back exercise on quality of life and back extensor strength in patients with osteoporosis: arandomized controlled trial. Osteoporos Int. 2007;18(10):1389-1395.
33. Madureira MM, Takayama L, Gallinaro AL, Caparbo VF, Costa RA, Pereira $\mathrm{RM}$. Balance training program is highly effective in improving functional status and reducing the risk of falls in elderly women with osteoporosis: a randomized controlled trial. Osteoporos Int. 2007;18(4):419-425.

34. Malmros B, Mortensen L, Jensen MB, Charles P. Positive effects of physiotherapy on chronic pain and performance in osteoporosis. Osteoporos Int. 1998;8(3):215-221.

35. Papaioannou A, Adachi JD, Winegard K, et al. Efficacy of home-based exercise for improving quality of life among elderly women with symptomatic osteoporosis related vertebral fractures. Osteoporos Int. 2003;14(8):677-682.

36. Sinaki M, Brey RH, Hughes CA, Larson DR, Kaufman KR. Significant reduction in risk of falls and back pain in osteoporotic-kyphotic women through a spinal proprioceptive extension exercise dynamic (SPEED) program. Mayo Clin Proc. 2005;80(7):849-855.

37. von Stengel S, Kemmler W, Kalender WA, Engelke K, Lauber D. Differential effects of strength versus power training on bone mineral density in postmenopausal women: a 2-year longitudinal study. $\mathrm{Br} J$ Sports Med. 2007;41(10):649-655; discussion 655.

38. Kronhed A-CG, Hallberg I, Ödkvist L, et al. Effect of training on health-related quality of life, pain and falls in osteoporotic women. Adv Physiother. 2009;11(3):154-165.

39. Sinaki M. Exercise for patients with osteoporosis: management of vertebral compression fractures and trunk strengthening for fall prevention. PM R. 2012;4(11):882-888.

40. Bautmans I, Van Arken J, Van Mackelenberg M, Mets T. Rehabilitation using manual mobilization for thoracic kyphosis in elderly postmenopausal patients with osteoporosis. J Rehabil Med. 2010;42(2):129-135.

41. Bennell KL, Matthews B, Greig A, et al. Effects of an exercise and manual therapy program on physical impairments, function and quality-of-life in people with osteoporotic vertebral fracture: a randomised, single-blind controlled pilot trial. BMC Musculoskelet Disord. 2010;11:1-11.

42. Huang LQ, He HC, He CQ, Chen J, Yang L. Clinical update of pulsed electromagnetic fields on osteoporosis. Chin Med J (Engl). 2008;121(20):2095-2099

43. Iwamoto J, Takeda T, Sato Y, Uzawa M. Effect of whole-body vibration exercise on lumbar bone mineral density, bone turnover, and chronic back pain in post-menopausal osteoporotic women treated with alendronate. Aging Clin Exp Res. 2005;17(2):157-163.

44. Iwamoto J, Sato Y, Takeda T, Matsumoto H. Whole body vibration exercise improves body balance and walking velocity in postmenopausal osteoporotic women treated with alendronate: Galileo and Alendronate Intervention Trail (GAIT). Musculoskelet Neuronal Interact. 2012;12(3):136-143.

45. Liu H, Liu Y, Yang L, et al. Curative effects of pulsed electromagnetic fields on postmenopausal osteoporosis. Sheng Wu Yi Xue Gong Cheng Xue Za Zhi. 2014;31(1):48-52. Chinese.

46. Klarner A, von Stengel S, Kemmler W, et al. Effects of two different types of whole body vibration on neuromuscular performance and body composition in postmenopausal women. Dtsch Med Wochenschr. 2011;136(42):2133-2139

47. Ruan XY, Jin FY, Liu YL, Peng ZL, Sun YG. Effects of vibration therapy on bone mineral density in postmenopausal women with osteoporosis. Chin Med J (Engl). 2008;121(13):1155-1158.

48. Ehde DM, Dillworth TM, Turner JA. Cognitive-behavioral therapy for individuals with chronic pain: efficacy, innovations, and directions for research. Am Psychol. 2014;69(2):153-166.

49. Hanscom DA, Brox JI, Bunnage R. Defining the role of cognitive behavioral therapy in treating chronic low back pain: an overview. Global Spine J. 2015;5(6):496-504.

50. Kabat-Zinn J. An outpatient program in behavioral medicine for chronic pain patients based on the practice of mindfulness meditation: theoretical considerations and preliminary results. Gen Hosp Psychiatry. 1982;4(1):33-47.

51. Kolodny A, Courtwright DT, Hwang CS, et al. The prescription drug opioid and heroin crisis: a public health approach to an epidemic of addiction. Annu Rev Public Health. 2015;36:559-574. 
52. World Health Organization. Cancer Pain Relief. 2nd ed. Geneva: WHO; 1996.

53. Vellucci R, Mediati RD, Ballerini G. Use of opioids for treatment of osteoporotic pain. Clin Cases Miner Bone Metab. 2014;11(3):173-176.

54. Gangji V, Appelboom T. Analgesic effect of intravenous pamidronate on chronic back pain due to osteoporotic vertebral fractures. Clin Rheumatol. 1999;18(3):266-267.

55. Ulivieri FM. Back pain treatment in post-menopausal osteoporosis with vertebral fractures. Aging Clin Exp Res. 2007;19(Suppl 3):21-23.

56. Iolascon G, Cisari C, Moretti A, Frizzi L, Gimigliano R, Gimigliano F. NSAIDs and opioids in management of fragility fractures. Aging Clin Exp Res. 2013;25(Suppl 1):S97-S100.

57. Gené E, Calvet X, Moron A, et al. Recommendations for the use of antiinflammatory drugs and indications for gastroprotection in emergency departments. Emergencias. 2009;21(4):295-300.

58. Vestergaard P, Hermann P, Jensen JE, Eiken P, Mosekilde L. Effects of paracetamol, non-steroidal anti-inflammatory drugs, acetylsalicylic acid, and opioids on bone mineral density and risk of fracture: results of the Danish Osteoporosis Prevention Study (DOPS). Osteoporos Int. 2012;23(4):1255-1265.

59. Williams LJ, Pasco JA, Henry MJ, et al. Paracetamol (acetaminophen) use, fracture and bone mineral density. Bone. 2011;48(6): $1277-1281$.

60. Krocker D, Ullrich H, Buttgereit F, et al. Influence of adjuvant pain medication on quality of life in the treatment of postmenopausal osteoporosis. Orthopade. 2008;37(5):435-439.

61. Labianca R, Sarzi-Puttini P, Zuccaro SM, Cherubino P, Vellucci R, Fornasari D. Adverse effects associated with non-opioid and opioid treatment in patients with chronic pain. Clin Drug Investig. 2012;32 (Suppl 1): 53-63.

62. Scheiman JM, Fendrick AM. Practical approaches to minimizing gastrointestinal and cardiovascular safety concerns with COX-2 inhibitors and NSAIDs. Arthritis Res Ther. 2005;7(Suppl 4):S23-S29.

63. Vargas-Schaffer G. Is the WHO analgesic ladder still valid? Twenty-four years of experience. Can Fam Physician. 2010;56(6):e202-e205.

64. Oral A, Küçükdeveci AA, Varela E, et al. Osteoporosis. The role of physical and rehabilitation medicine physicians. The European perspective based on the best evidence. A paper by the UEMS-PRM Section Professional Practice Committee. Eur J Phys Rehabil Med 2013;49(4):565-577.

65. Lappe JM, Davies KM, Travers-Gustafson D, Heaney RP. Vitamin D status in a rural postmenopausal female population. $J$ Am Coll Nutr. 2006;25(5):395-402.

66. Catalano A, Morabito N, Atteritano M, Basile G, Cucinotta D, Lasco A. Vitamin D reduces musculoskeletal pain after infusion of zoledronic acid for postmenopausal osteoporosis. Calcif Tissue Int. 2012;90(4):279-285.

67. Plotnikoff GA, Quigley JM. Prevalence of severe hypovitaminosis D in patients with persistent, nonspecific musculoskeletal pain. Mayo Clinic Proc. 2003;78(12):1463-1470.

68. Cummings SR, San Martin J, McClung MR, et al; FREEDOM Trial. Denosumab for prevention of fractures in postmenopausal women with osteoporosis. N Engl J Med. 2009;361(8):756-765.

69. Petranova T, Sheytanov I, Monov S, Nestorova R, Rashkov R. Denosumab improves bone mineral density and microarchitecture and reduces bone pain in women with osteoporosis with and without glucocorticoid treatment. Biotechnol Biotechnol Equip. 2014;28(6):1127-1137.

70. Rogers MJ, Crockett JC, Coxon FP, Mönkkönen J. Biochemical and molecular mechanisms of action of bisphosphonates. Bone. 2011;49(1):34-41.

71. Black DM, Thompson DE, Bauer DC, et al; Fracture Intervention Trial. Fracture risk reduction with alendronate in women with osteoporosis: the fracture intervention trial. FIT research group. $J$ Clin Endocrinol Metab. 2000;85(11):4118-4124

72. Iwamoto J, Takeda T, Sato Y, Uzawa M. Effects of alendronate on metacarpal and lumbar bone mineral density, bone resorption, and chronic back pain in postmenopausal women with osteoporosis. Clin Rheumatol. 2004;23(5):383-389.
73. Dursun N, Dursun E, Yalcin S. Comparison of alendronate, calcitonin and calcium treatments in postmenopausal osteoporosis. Int $J$ Clin Pract. 2001;55(8):505-509.

74. Kawate H, Ohnaka K, Adachi M, et al. Alendronate improves QOL of postmenopausal women with osteoporosis. Clin Interv Aging. 2010;5:123-131.

75. Iwamoto J, Makita K, Sato Y, Takeda T, Matsumoto H. Alendronate is more effective than elcatonin in improving pain and quality of life in postmenopausal women with osteoporosis. Osteoporos Int. 2011;22(10):2735-2742.

76. Rozkydal Z, Janicek P. The effect of alendronate in the treatment of postmenopausal osteoporosis. Bratisl Lek Listy. 2003;104(10):309-313.

77. Iwamoto J, Takeda T, Ichimura S, Uzawa M. Early response to alendronate after treatment with etidronate in postmenopausal women with osteoporosis. Keio J Med. 2003;52(2):113-119.

78. Alekseeva LI, Zaitseva EM, Sharapova EP, et al. [Evaluation of the efficacy and tolerance of ibandronic acid in patients with osteoarthrosis in the knee joints concurrent with osteoporosis: a pilot study]. Ter Arkh. 2013;85(5):30-36.

79. Yoshioka T, Okimoto N, Okamoto K, Sakai A. A comparative study of the effects of daily minodronate and weekly alendronate on upper gastrointestinal symptoms, bone resorption, and back pain in postmenopausal osteoporosis patients. J Bone Miner Metab. 2013;31(2):153-160.

80. Ohtori S, Akazawa T, Murata Y, et al. Risedronate decreases bone resorption and improves low back pain in postmenopausal osteoporosis patients without vertebral fractures. J Clin Neurosci. 2010;17(2): 209-213.

81. Muratore M, Calcagnile F, Quarta E. Antalgic efficacy of the bisphosphonates in vertebral fractures of recent onset. Osteoporos Int. 2004;15(Suppl 1):S121.

82. Muratore M, Canaparo R, Della Pepa C, et al. Bisphosphonates antalgic activity in recent vertebral fracture: a clodronate vs neridronate comparison. Osteoporos Int. 2004;15(Suppl 1):S119.

83. Koivisto K, Kyllönen E, Haapea M, et al. Efficacy of zoledronic acid for chronic low back pain associated with Modic changes in magnetic resonance imaging. BMC Musculoskelet Disord. 2014;15:64.

84. Cauley JA, Black D, Boonen S, et al; HORIZON Pivotal Fracture Group. HORIZON Pivotal Fracture Group. Once-yearly zoledronic acid and days of disability, bed rest, and back pain: randomized, controlled HORIZON Pivotal Fracture Trial. J Bone Miner Res. 2011;26(5): 984-992.

85. D'Amelio P, Tamone C, Sassi F, et al. Teriparatide increases the maturation of circulating osteoblast precursors. Osteoporos Int. 2012; 23(4):1245-1253.

86. Devogelaer JP, Boutsen Y, Manicourt DH. Biologicals in osteoporosis: teriparatide and parathyroid hormone in women and men. Curr Osteoporos Rep. 2010;8(3):154-161.

87. Iolascon G, Gimigliano F, Malavolta N, et al. Effectiveness of teriparatide treatment on back pain-related functional limitations in individuals affected by severe osteoporosis: a prospective pilot study. Clin Cases Miner Bone Metab. 2012;9(3):161-165.

88. Nevitt MC, Chen P, Dore RK, et al. Reduced risk of back pain following teriparatide treatment: a meta-analysis. Osteoporos Int. 2006; 17(2):273-280.

89. Fahrleitner-Pammer A, Langdahl BL, Marin F, et al. Fracture rate and back pain during and after discontinuation of teriparatide: 36-month data from the European Forsteo Observational Study (EFOS). Osteoporos Int. 2011;22(10):2709-2719.

90. Lyritis G, Marin F, Barker C, et al; EUROFORS Study Group. Back pain during different sequential treatment regimens of teriparatide: results from EUROFORS. Curr Med Res Opin. 2010;26(8):1799-1807.

91. Songpatanasilp T, Mumtaz M, Chhabra H, Yu M, Sorsaburu S. Back pain in patients with severe osteoporosis on teriparatide or antiresorptives: a prospective observational study in a multiethnic population. Singapore Med J. 2014;55(9):493-501.

92. Manuele S, Sorbello L, Puglisi N, et al. The teriparatide in the treatment of severe senile osteoporosis. Arch Gerontol Geriatr. 2007;44 (Suppl 1): 249-258. 
93. Meunier PJ, Roux C, Seeman E, et al. The effects of strontium ranelate on the risk of vertebral fracture in women with postmenopausal osteoporosis. N Engl J Med. 2004;350(5):459-468.

94. Bonnelye E, Chabadel A, Saltel F, Jurdic P. Dual effect of strontium ranelate: stimulation of osteoblast differentiation and inhibition of osteoclast formation and resorption in vitro. Bone. 2008;42(1):129-138.

95. Kaufman JM, Audran M, Bianchi G, et al. Efficacy and safety of strontium ranelate in the treatment of osteoporosis in men. J Clin Endocrinol Metab. 2013;98(2):592-601.

96. Negri AL, Spivacow FR. Healing of subtrochanteric atypical fractures after strontium ranelate treatment. Clin Cases Miner Bone Metab. 2012;9(3):166-169.

97. Meunier PJ, Roux C, Ortolani S, et al. Effects of long-term strontium ranelate treatment on vertebral fracture risk in postmenopausal women with osteoporosis. Osteoporos Int. 2009;20(10):1663-1673.

98. Ringe JD, Dorst A, Farahmand P. Efficacy of strontium ranelate on bone mineral density in men with osteoporosis. Arzneimittelforschung. 2010;60(5):267-272.

99. Cianferrotti L, D’Asta F, Brandi ML. A review on strontium ranelate long-term antifracture efficacy in the treatment of postmenopausal osteoporosis. Ther Adv Musculoskel Dis. 2013;5(3):127-139.

100. Cranney A, Tugwell P, Zytaruk N, et al; Osteoporosis Methodology Group and The Osteoporosis Research Advisory Group. Meta-analyses of therapies for postmenopausal osteoporosis. VI. Meta-analysis of calcitonin for the treatment of postmenopausal osteoporosis. Endocr Rev. 2002;23(4):540-551.

101. Downs RW Jr, Bell NH, Ettinger MP, et al. Comparison of alendronate and intranasal calcitonin for treatment of osteoporosis in postmenopausal women. J Clin Endocrinol Metab. 2000;85(5): 1783-1788.
102. Shibata K, Takeda M, Ito A, Takeda M, Sagai H. Ovariectomyinduced hyperalgesia and antinociceptive effect of elcatonin, a synthetic eel calcitonin. Pharmacol Biochem Behav. 1998;60(2):371-376.

103. Blau LA, Hoehns JD. Analgesic efficacy of calcitonin for vertebral fracture pain. Ann Pharmacother. 2003;37(4):564-570.

104. Scharla S, Oertel H, Helsberg K, Kessler F, Langer F, Nickelsen T. Skeletal pain in postmenopausal women with osteoporosis: prevalence and course during raloxifene treatment in a prospective observational study of 6 months duration. Curr Med Res Opin. 2006;22(12):2393-2402.

105. Papadokostakis G, Katonis P, Damilakis J, Hadjipavlou A. Does raloxifene treatment influence back pain and disability among postmenopausal women with osteoporosis? Eur Spine J. 2005; 14(10):977-981.

106. Macías-Hernández SI, Chávez-Arias DD, Miranda-Duarte A, Coronado-Zarco R, Diez-García MP. Percutaneous vertebroplasty versus conservative treatment and rehabilitation in women with vertebral fractures due to osteoporosis: a prospective comparative study. Rev Invest Clin. 2015;67(2):98-103.

107. Metcalfe D. The pathophysiology of osteoporotic hip fracture. Mcgill J Med. 2008;11(1):51-57.

108. Mears SC. Management of severe osteoporosis in primary total hip arthroplasty. Geriatr Orthop. 2013;2(2):99-104.

109. Gewandter JS, Dworkin RH, Turk DC, et al. Research designs for proofof-concept chronic pain clinical trials: IMMPACT recommendations. Pain. 2014;155(9):1683-1695.
Journal of Pain Research

\section{Publish your work in this journal}

The Journal of Pain Research is an international, peer-reviewed, open access, online journal that welcomes laboratory and clinical findings in the fields of pain research and the prevention and management of pain. Original research, reviews, symposium reports, hypothesis formation and commentaries are all considered for publication.

\section{Dovepress}

The manuscript management system is completely online and includes a very quick and fair peer-review system, which is all easy to use. Visit http://www.dovepress.com/testimonials.php to read real quotes from published authors. 